had no eyes. The only other etiologic moment the family recalls is a fright of the mother during a severe thunderstorm which occurred about three weeks before delivery. It is hardly necessary to say that neither of these causes could be given any consideration. Everything points to a severe inflammation. At my suggestion Dr. Rappoport has made a microscopic examination of the ocular discharge of the infant, and he reports to me the presence of diplococci which did not respond to the gonococcic stain.

There is no doubt in my mind that we deal here with a case of phthisis bulbi, resulting from a suppurative intra-uterine uveitis. The marked local inflammatory symptoms, the absence of any other anatomic anomaly, the pustular eruption on the mother four weeks before the delivery of the child, the presence of the diplococcus in the ocular discharge, and the appearance of the stump make the diagnosis of phthisis bulbi certain. Of course the number of cases of microphthalmus reported in the literature are many, but most of them were the result of some arrest of development.

Opinions on this subject are divided. Hirschberg, von Graefe, Samelsohn and Deutschmann advanced the theory of intra-uterine inflammation, while the developmental theory was defended by Hess and Treacher Collins. There is, however, a definite group of cases in which there can be no reasonable doubt that the condition is one of congenital phthisis bulbi. This is especially true of Schaumberg' $\mathrm{s}^{1}$ case in which the eye continued to shrink after birth. In my case the inflammatory cause is well substantiated by clinical evidence and laboratory findings.

917 Spruce Street.

\section{A SEVERE CASE OF EXOPHTHALMIC GOITER, WITH COMPLETE RECOVERY WITHOUT OPERATION, REST OR MEDICATION}

\section{Edward Swasey, M.D., Worcester, Mass.} Oculist and Aurist to Worcester City Hospital

It may not be safe or profitable to draw conclusions from any one case of illness, either medical or surgical; and yet a single case may present some features of importance and interest that may render its history worthy of public record. I believe the following case is in this class:

Mary M. is now 24 years of age. When she was $12 \mathrm{I}$ gave her glasses for a rather high degree of astigmatism. She has been under my observation at intervals for these past twelve years. Some five or more years ago her mother first noticed a growth in the neck. This rather rapidiy increased in size so that the neck band of her dresses required frequent enlargement. The girl soon began to show signs of nervousness, was easily fatigued, and complained of palpitation on slight exertion. Soon the eyes seemed to enlarge and become prominent. She consulted her family physician who gave her some simple tonics for her evident weakness.

Some months later she came to my office to see if some change in her lenses wạs necessary. The change in her appearance since her last visit one year before was decided, for now there were all the classical signs and symptoms of a typical case of exophthalmic goiter. The eyes were bulging, so that a line of white sclerotic was seen between the iris and the upper lid. The swelling in the neck was firm and pulsating; the pulse was then more than 150 per minute, soft and compressible. The ear or hand over the cardiac area showed a large pulsating heart, in rapid action. In

1. Schaumberg: Dissertation, Marburg, 1881. fact, all the signs and symptoms of a well-established case of Graves' disease were present. I have had the case under observation from that time to the present. I gave her no medicine, but for a time she had a simple tonic from her physician and also from one of the city dispensaries.

The chief interest in this case, I believe, is not that she has entirely recovered, and that all her symptoms have disappeared; but that during the entire duration of these severe symptoms she was daily at her work at the counter of one of the largest department stores in the city. She continued her tonics for a year or more in a somewhat irregular way, but finding no benefit from their use gave them up entirely. A year or more after she had given up all medication she began to improve, in that she felt stronger and more able to do her work; the heart action was less troublesome, the swelling of the neck less evident. This improvement has gone slowly but steadily on until now (for I saw her but a few days since) the neck is free from any swelling, and palpation reveals no thyroid enlargement; the pulse is strong, steady and under 80 per minute; the eyes have returned to the normal in position and appearance. She has never taken any of the modern powders or serums that are now given for this trouble. She has never taken any season of rest in bed, but, on the contrary, has taken no vacation, but worked on. In the months that the symptoms were at their worst I felt certain she would have to come to a surgical operation to save her from the severe toxemia that I thought might overwhelm her in a severe attack of diarrhea or fatal exhaustion; but she said she must keep at her work and would not listen to advice for an operation.

I have recently followed the case of a patient in whom the symptoms were not more severe than in this poor girl, and not so long in duration, that finally came to operation in the Johns Hopkins Hospital, but the patient survived the operation but a few hours. I have had for a number of years a patient who has the eye symptoms and enlarged thyroid. Both of these have been stationary for years.

It may be that cases similar to this are common, and in a somewhat careful search in the literature of the subject I find many recorded cases of recovery, of course; but I have yet to find the history of one with severe symptoms for many months and a total duration of more than five years, yet going on to complete recovery that has not had prolonged course of treatment, either by rest in bed, the use of the modern drugs, the application of some external treatment to the thyroid, the Roentgen ray, or one or all of these at different times. Hence I believe that the case of this patient who had no treatment, but just work, and plenty of it, and yet has gone on to complete recovery, deserves a place in the records of this serious disease.

The question may arise regarding the subsequent history of this patient. Will this great and prolonged activity of the thyroid finally result in an atrophy more or less complete and cause a myxedema? It will be interesting to watch the patient for a few years.

390 Main Street.

\section{TRAUMATIC RUPTURE OF THE HEALTHY AORTA WITHOUT EXTERNAL SIGNS OF THE CAUSE OF DEATH}

\section{Gordon Grote Copeland, B.A., M.B., Toronto}

Complete rupture of the healthy aorta without external signs of the cause of death is of sufficient rarity to warrant the publication of a synopsis of necropsy which I made recently.

A laborer, aged about 40 years, was struck by a large mass of falling earth which gave him a glancing blow on the back and knocked him down, though it covered only his legs. A few seconds later he was picked up dead, and was seen by a medical man in a few minutes who could find no cause externally for the sudden death. I examined the body a few hours later but saw no apparent cause of death. There was a large scalp wound on the forehead down to the bone, 